\title{
Mass Transfer Phenomena and Hydrodynamics in Agitated Gas-Liquid Reactors and Bubble Columns at Elevated Pressures: State of the Art
}

\author{
Stoffübergangserscheinungen und Hydrodynamik in gerührten \\ Gas-Flüssigkeitsreaktoren und Blasensäulen bei hohen Drucken: \\ Stand der Technik
}

\author{
M. H. OYEVAAR* and K. R. WESTERTERP** \\ Department of Chemical Engineering, Chemical Reaction Engineering Laboratories, Twente University, \\ P.O. Box 217, 7500 AE Enschede (The Netherlands)
}

(Received September 26, 1988; in final form January 13, 1989)

\begin{abstract} contactors are available.

\section{Introduction}

Gas-liquid contacting is an operation often used in the process industry. In this operation the gasliquid mass transfer may represent a major resistance to the rate of absorption or desorption. The governing factors, for example, the mass transfer coefficient, the interfacial area and the gas hold-up, are determined largely by the choice of the reactor type. Within practical boundaries they can be varied only in between certain limits by changing the flow rates, the reactor geometry or the degree of turbulence. The gas-liquid mass transfer can also be improved by increasing the driving force for the mass transfer. This can be realized through an increase in the concentration of the component being absorbed, either by increasing the partial pressure of the component or the total pressure in the reactor.

Only in the past two decades has some research been reported on the influence of the operating pressure on the mass transfer characteristics in different
\end{abstract}

All important studies on the influence of pressure on mass transfer phenomena in gas-liquid systems and reactors are reviewed critically. Points of agreement and conflict are indicated and discussed.

It is concluded that: (1) the initial bubble size at a single orifice decreases with increasing pressure; (2) the gas-phase mass transfer coefficient $k_{\mathrm{G}}$ is inversely proportional to the pressure to the power $n$, where $n$ depends on the mass transfer mechanism; (3) the liquid-phase mass transfer coefficient $k_{\mathrm{L}}$ is not influenced by pressure; (4) the gas hold-up $\varepsilon_{\mathrm{G}}$ in bubble columns increases with increasing pressure.

However, insufficient data on the influence of the operating pressure on the interfacial areas in gas-liquid

\footnotetext{
* Present address: General Electric Plastics bv, Bergen op Zoom, The Netherlands.

**Author to whom correspondence should be addressed.
}

reactor types, although it has been known for a long time that some high pressure gas-liquid reactors operate with extremely high gas hold-ups $[1,2]$. The few results for different reactors and gas-liquid systems which have been reported up till now contradict each other regarding the effect of the operating pressure on the interfacial area and the gas hold-up. Changes up to twofold in the gas hold-up have been reported [1-5] in two- and three-phase bubble columns operating up to $15 \mathrm{MPa}$. On the other hand, gas hold-up measurements [6-8] in bubble columns up to $2.0 \mathrm{MPa}$ show no effect of the reactor pressure. The same contradictions are reported for mechanically agitated reactors, where Vafopulos et al. [6] and Albal et al. $[9,10]$ found no influence of the pressure on the volumetric liquid-phase mass transfer coefficient and on the interfacial area, while Sridhar and Potter $[11,12]$ report an increase in the interfacial area of as much as $75 \%$ for a pressure increase from 0.1 to $1.1 \mathrm{MPa}$. The contradictory results of the above-mentioned authors can lead to considerable miscalculations, whatever correlation is taken.

In this paper all major studies on the influence of pressure on mass transfer phenomena in gas-liquid systems and reactors are reviewed critically. Points of agreement and conflict are indicated and discussed in order to improve understanding of the mass transfer 
phenomena in pressurized gas-liquid reactors. The major conclusions and points of conflict are given at the end of the paper.

\section{Pressure review}

Some twenty papers have been published which deal with or touch upon the influence of the operating pressure in gas-liquid systems. They can be subdivided roughly into three groups dealing with the influence of the operating pressure on:

(1) the formation and coalescence behaviour of single bubbles in gas-liquid systems;

(2) the gas- and liquid-phase mass transfer coefficients in gas-liquid reactors;

(3) the volumetric liquid-phase mass transfer coefficient, the interfacial area and the gas hold-up in gas-liquid reactors.

In the next three sections these groups will be discussed separately. It is important to note that in mentioning gas flow rates we shall always base them on the volumetric rates. This means that at constant volumetric flow rates the mass flow rates are increased with pressure because of the increasing density. Superficial gas velocities as used by us therefore refer to the volumetric gas flow rate at the pressure in the reactor divided by the empty cross-sectional area of the reactor.

\subsection{Formation and coalescence behaviour of single bubbles}

All studies concerning the influence of pressure on the formation of bubbles have been performed at single orifices connected either to a gas chamber or a capillary tube. Details of these studies on, for example, the operating pressure, the system properties and the influence of the operating pressure are summarized in Table 1.

Kling [13] was the first to observe that an increase in the operating pressure at equal superficial gas velocity and at a single gas inlet orifice causes a decrease in the initial bubble volume. Consequently, the bubble frequency at the orifice increases. Kling [13] suggested that the increase in energy content causes the gas to penetrate deeper into the liquid, leading to more oblong bubbles which detach more easily from the orifice. This results in smaller bubbles at higher pressures.

LaNauze and Harris [14] investigated photographically the formation of $\mathrm{CO}_{2}$ bubbles in water at three orifices with different diameters at pressures up to $2.1 \mathrm{MPa}$. At atmospheric pressure they observed a linear increase in the initial bubble volume with increasing gas flow rate. At higher pressures the bubble volume no longer shows this linear dependence and an increase in the gas flow rate is accompanied by a simultaneous increase in the bubble volume and the bubble frequency (see Fig. 1 (Fig. 7 of ref. 14)). With regard to the effect of the operating pressure the bubble volume decreases by about $50 \%$

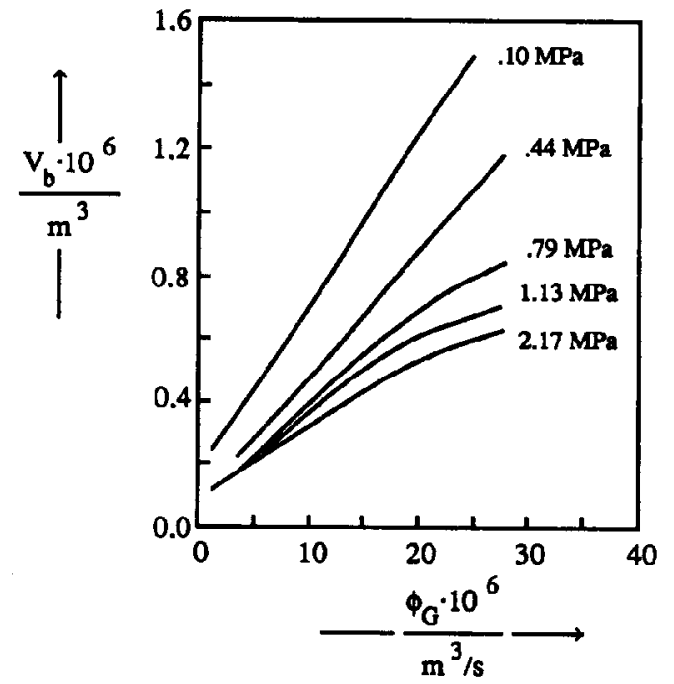

Fig. 1. Bubble volume against the gas flow rate at different pressures; $\mathrm{CO}_{2}$-water, $d_{\mathrm{or}}=4.8 \mathrm{~mm}$ (Fig. 7 of LaNauze and Harris [14]).

with an increase from 0.1 to $1 \mathrm{MPa}$, but after that only slightly from 1 to $2.1 \mathrm{MPa}$ (see Fig. 2 (Fig. 10 of ref. 14)). This reduction in initial bubble volume results in a large degree of interaction and coalescence near the orifice at higher mass flow rates. LaNauze and Harris [14] attributed the reduction in the size of the bubbles and the higher formation frequency to the increased contribution of the momentum of the gas to the bubble formation process, caused by higher pressures or by higher flow rates.

The experiments of Bier et al. [15] showed a rather similar dependence of the initial bubble volume on the operating pressure. Their experimental technique consisted of sparging $\mathrm{N}_{2}, \mathrm{He}$ or $\mathrm{SF}_{6}$ through a single orifice into water, ethanol or a refrigerant. However, these authors find a much

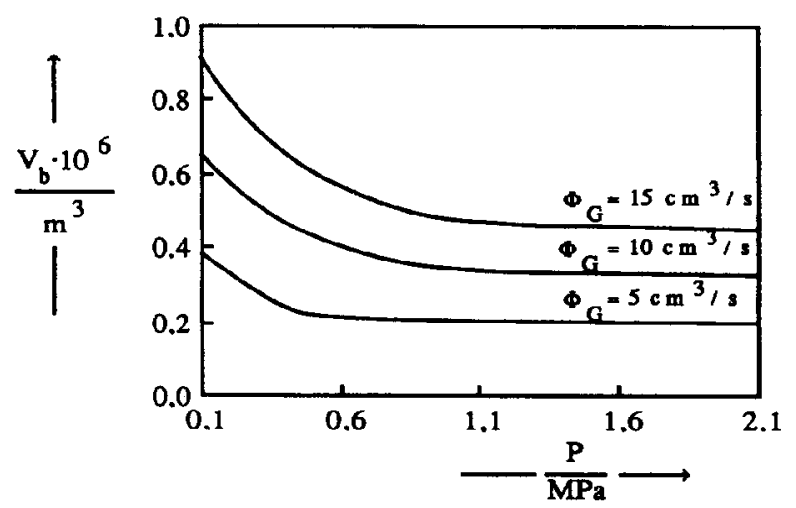

Fig. 2. Bubble volume against the pressure at different gas flow rates; $\mathrm{CO}_{2}$-water, $d_{\mathrm{or}}=4.8 \mathrm{~mm}$ (Fig. 10 of LaNauze and Harris [14]). 


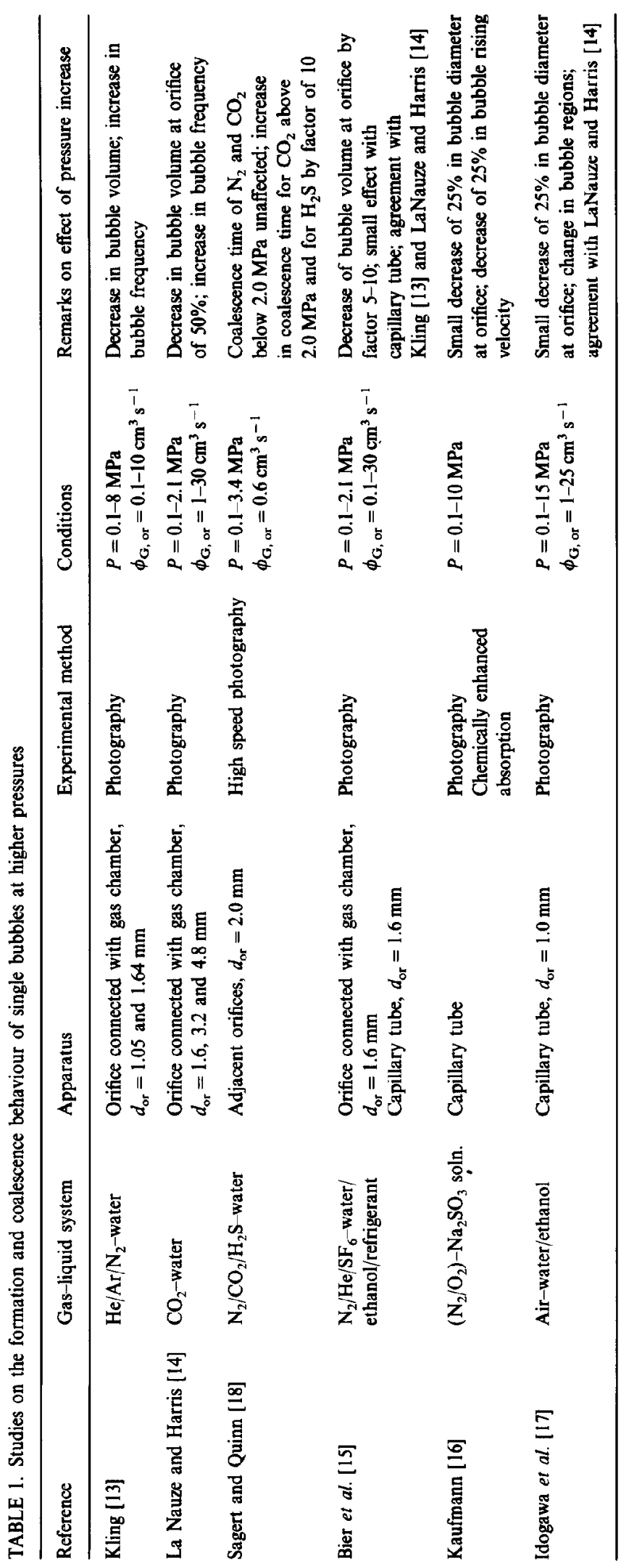


smaller influence of the operating pressure if the gas is sparged through a capillary tube instead of through an orifice connected to a gas chamber. This gas chamber, of course, prevents the pressure oscillations which occur in narrow gas supply lines. Kaufmann [16] determined the diameter of bubbles formed by injection of a $\mathrm{N}_{2} / \mathrm{O}_{2}$ mixture in a sodium sulphite solution through a capillary tube at pressures up to $10 \mathrm{MPa}$. He observed a slight decrease of $25 \%$ in the bubble diameter with a pressure increase from 0.1 to $10 \mathrm{MPa}$.

Idogawa et al. [17] observed the bubble formation at a single orifice in air-water and air-ethanol systems for pressures up to $15 \mathrm{MPa}$. They reported a decrease in the initial bubble diameter of $25 \%$ at a pressure increase from 0.1 to $15 \mathrm{MPa}$. The critical gas velocity separating the multiple bubbling and jetting regions decreased with increasing pressure. This critical gas velocity was correlated in an equation based on their own measurements, the results of LaNauze and Harris [14], and on some atmospheric results:

$\mathrm{We}_{\text {cr. or }}=1.4 \times 10^{36} \mathrm{Re}_{\mathrm{G.} \mathrm{or}}{ }^{-8}$

The Weber and the Reynolds number are both based on the orifice diameter and the orifice velocity; $\mathrm{Re}$ ranges from $4 \times 10^{3}$ up to $2.5 \times 10^{4}$. Gas velocities which result in a value below $\mathrm{We}_{\mathrm{cr} \text {, or }}$ and with $\mathrm{Re}_{\mathrm{G}, \text { or }}>10^{4}$ result in the formation of single bubbles. Above the critical Weber number jetting occurs.

Sagert and Quinn [18] measured, with high speed photography, the coalescence time of two $\mathrm{N}_{2}, \mathrm{CO}_{2}$ or $\mathrm{H}_{2} \mathrm{~S}$ bubbles in water at pressures up to $3.4 \mathrm{MPa}$. They observed no influence of the operating pressure on the coalescence time of $\mathrm{N}_{2}$ bubbles and below 2.0 MPa no influence on the coalescence time of $\mathrm{CO}_{2}$ bubbles. However, for $\mathrm{CO}_{2}$ the coalescence time rises from $2-3 \mathrm{~ms}$ at $2.0 \mathrm{MPa}$ to $20 \mathrm{~ms}$ at $3.4 \mathrm{MPa}$. For $\mathrm{H}_{2} \mathrm{~S}$ bubbles the coalescence time depends strongly on the pressure and rises from around $10 \mathrm{~ms}$ at $0.1 \mathrm{MPa}$ to $100 \mathrm{~ms}$ at $1.5 \mathrm{MPa}$. The authors postulated that specific interactions of the gas with the aqueous surface layers are responsible for the increase in the coalescence time.

Altogether it can be concluded that there exists good agreement on the influence of pressure on the bubble formation at single orifices. An increase in the system pressure causes a decrease in the initial bubble size and an increase in the bubble frequency, which result in a large degree of interaction near the orifice. The effect of pressure is larger if the orifice is connected to a gas chamber instead of a capillary tube. This is shown in Figs. 3 and 4 in which normalized bubble volumes of all the studies mentioned are plotted against the pressure for an orifice connected to a gas chamber and a capillary tube respectively. The bubble volumes at a single orifice connected to a gas chamber decrease by about a factor of 3 with an increase in pressure from 0.1 to 2.0 MPa. The decrease in the bubble volumes at a

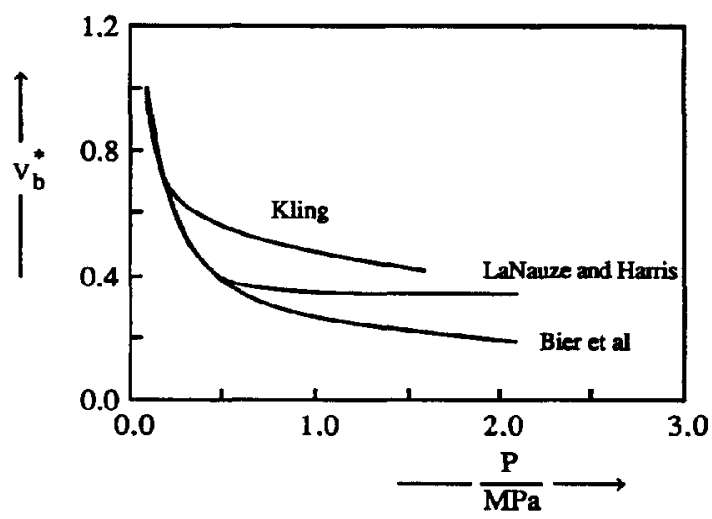

Fig. 3. Normalized bubble volume against the pressure for an orifice connected to a gas chamber; $\phi_{\mathrm{G} \text {, or }}=5 \mathrm{~cm}^{3} \mathrm{~s}^{-1}$.

\begin{tabular}{lll}
\hline Reference & Gas-liquid system & $d_{\text {or }}(\mathrm{mm})$ \\
\hline LaNauze and Harris [14] & $\mathrm{CO}_{2}$-water & 1.05 \\
Kling [13] & $\mathrm{N}_{2}$-water & 1.6 \\
Bier et al. [15] & $\mathrm{N}_{2}$-water & 1.6 \\
\hline
\end{tabular}

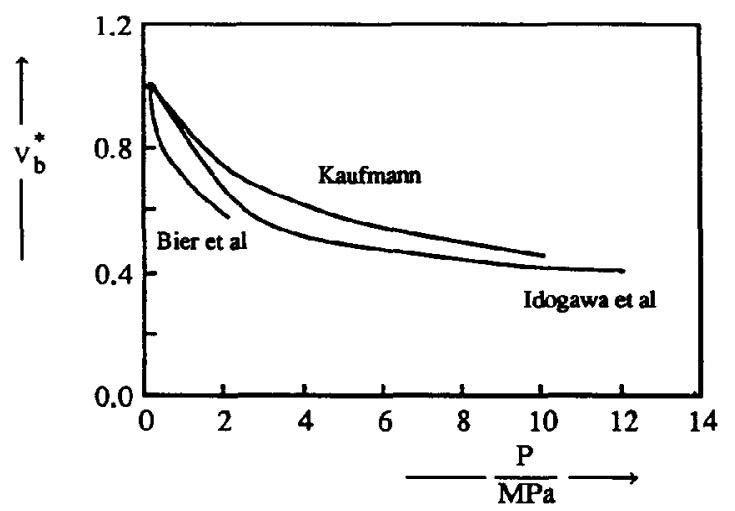

Fig. 4. Normalized bubble volume against the pressure for a capillary tube.

\begin{tabular}{llll}
\hline Reference & $\begin{array}{l}\text { Gas-liquid } \\
\text { system }\end{array}$ & $\phi_{\mathrm{G}, \text { or }}\left(\mathrm{cm}^{3} \mathrm{~s}^{-1}\right)$ & $d_{\mathrm{or}}(\mathrm{mm})$ \\
\hline Kaufmann [16] & $\begin{array}{l}\mathrm{N}_{2} / \mathrm{O}_{2}- \\
\mathrm{Na}_{2} \mathrm{SO}_{3} \text { soln. }\end{array}$ & 0.5 & \\
$\begin{array}{l}\text { Air-water } \\
\begin{array}{c}\text { et al. } \text { [4] } \\
\text { Bier } \text { et al. [15] }\end{array}\end{array}$ & \begin{tabular}{l}
$\mathrm{N}_{2}$-water \\
\hline
\end{tabular} & 5 & 1 \\
\hline
\end{tabular}

capillary tube is of the same order of magnitude; however, a sixfold increase in pressure from 0.1 to $12 \mathrm{MPa}$ is needed to accomplish this. Coalescence measurements for some specific gases also indicate that the coalescence time increases at higher pressures. 


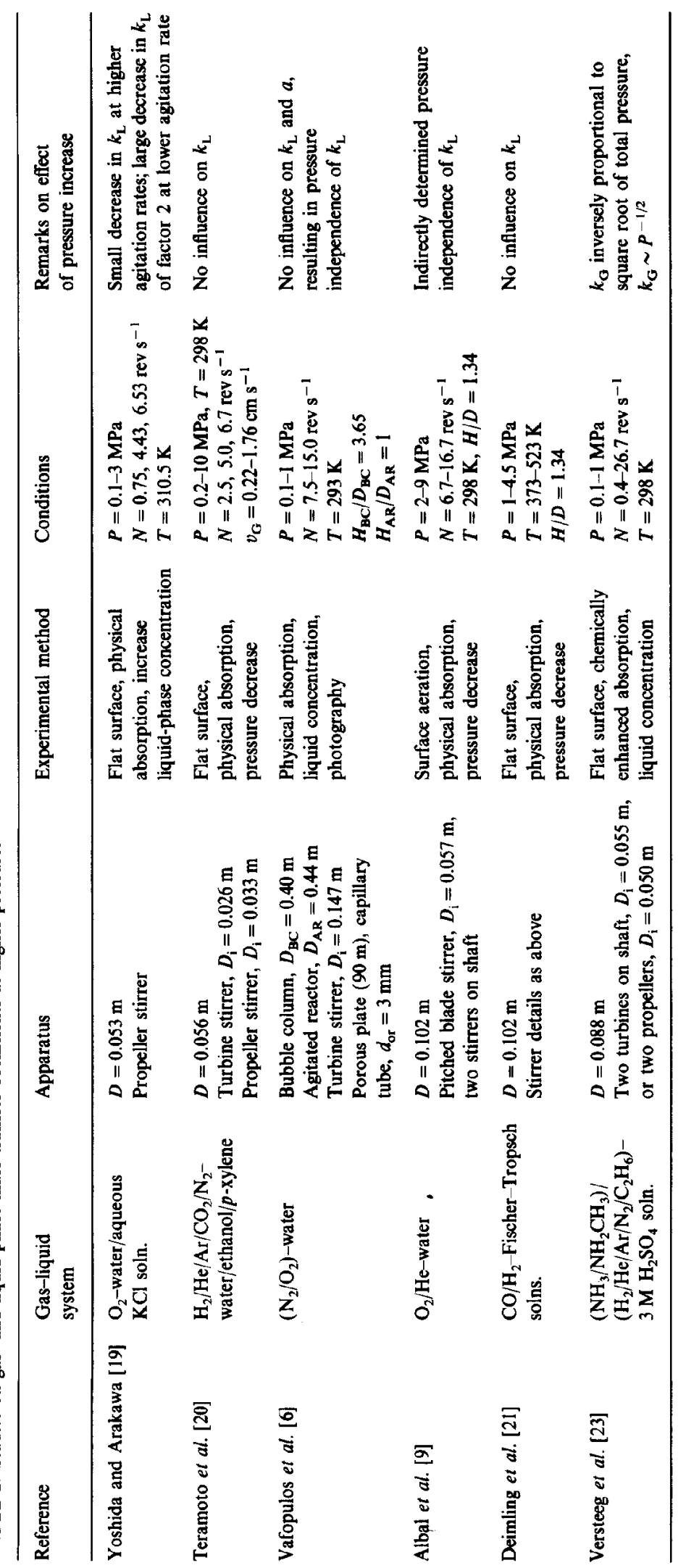




\subsection{Gas- and liquid-phase mass transfer coefficients}

In most studies the influence of the operating pressure on the gas- and liquid-phase mass transfer coefficients $k_{\mathrm{G}}$ and $k_{\mathrm{L}}$ is determined in stirred autoclaves with a flat surface. Vafopulos et al. [6] are the only ones to report on liquid-phase mass transfer coefficients at higher pressures in a bubble column and a mechanically agitated reactor. Details of these studies are given in Table 2.

In a stirred autoclave at pressures between 0.1 and $3 \mathrm{MPa}$ Yoshida and Arakawa [19] determined liquidphase mass transfer coefficients for the systems of oxygen in water and oxygen in an aqueous $\mathrm{KCl}$ solution. They observed a small decrease of $k_{\mathrm{L}}$ with pressure at higher agitation rates and a large decrease by a factor of 2 in $k_{\mathrm{L}}$ at the lower agitation rate with a pressure increase from 0.5 to $2.0 \mathrm{MPa}$. They suggest that the pressurc dependence of $k_{\mathrm{L}}$ is due to a change in the surface renewal rate or the degree of interfacial turbulence, which could be accounted for by the change in surface tension due to the gas pressure.

Contrary to these results, Teramoto et al. [20], using a stirred autoclave with a flat surface, observed no influence on $k_{\mathrm{L}}$ of operating pressures between 0.2 and $10 \mathrm{MPa}$ in absorption measurements with various gases into water, ethanol and $p$-xylene. This was confirmed by Albal et al. [9], who worked with $\mathrm{O}_{2}$-water and $\mathrm{He}$-water as gas-liquid systems, at pressures between 2 and $9 \mathrm{MPa}$. For three different Fischer-Tropsch-type liquids and working at pressures ranging from 1 to $5 \mathrm{MPa}$, Deimling et al. [21] also mentioned that they observed no relation between $k_{\mathrm{L}}$ and pressure in a stirred autoclave with a flat surface. These authors explained their results by the fact that pressure does not change significantly the physical properties of a liquid and therefore does not affect the liquid-phase diffusivity of the gas.

In air-water systems, Vafopulos et al. [6] determined separately the volumetric liquid-phase mass transfer coefficients $k_{\mathrm{L}} a$ by physical absorption and the interfacial areas $a$ by photography. They worked with a bubble column and a mechanically agitated reactor at pressures ranging from 0.1 to $1 \mathrm{MPa}$. From these results they calculated values for the liquid-phase mass transfer coefficient which appeared to be independent of pressure. Vafopulos et al. [6] also explained the pressure independence of $k_{\mathrm{L}}$ by the fact that the liquid-phase properties are not affected by pressure.

In contrast, the gas-phase mass transfer coefficient $k_{\mathrm{G}}$ could indeed be influenced by pressure, because the diffusivity is inversely proportional to the total system pressure, for in ideal gases the product of the density and the diffusivity is constant [22]. Up till now only Versteeg et al. [23] have determined gasphase mass transfer coefficients $k_{\mathrm{G}}$ at elevated pressures between 0.1 and $1 \mathrm{MPa}$. In a stirred autoclave with a flat interface they did so by absorption of a diluted gas-phase component from an inert gas phase into a liquid where an instantaneous reaction occurs

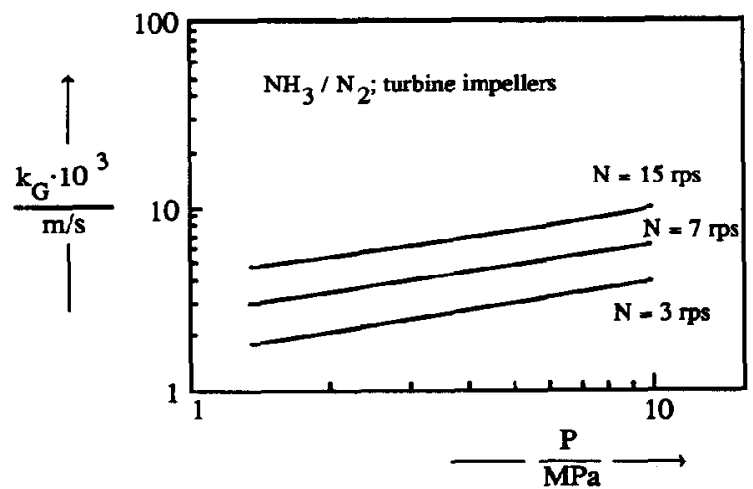

Fig. 5. Gas-phase mass transfer coefficient against the pressure at different agitation rates [23].

between the absorbed component and a liquid-phase reactant. The gas-phase mass transfer coefficient appeared to be inversely proportional to the square root of the pressure, as predicted by the penetration theory (see Fig. 5).

Except for the results of Yoshida and Arakawa [19], all studies indicate that the operating pressure has no influence on the liquid-phase mass transfer coefficient $k_{\mathrm{L}}$. This seems rather obvious because there is no influence of pressure on the liquid-phase properties. The gas-phase mass transfer coefficient $k_{\mathrm{G}}$ seems to depend on the operating pressure. The results of Versteeg et al. [23] indicate that

$k_{\mathrm{G}} \approx P^{-0.5}$

where the value of the exponent corresponds to the predictions of the penetration mechanism.

\subsection{Volumetric liquid-phase mass transfer coefficients, interfacial areas and gas hold-ups}

Most studies in pressurized gas-liquid systems concern the influence of pressure on the overall mass transfer parameters $k_{\mathrm{L}} a, a$, and the gas hold-up $\varepsilon_{\mathrm{G}}$ in agitated reactors and bubble columns. They are discussed in the next two sections and the details are summarized in Tables 3 and 4 respectively. It will be shown that there is no general agreement among the authors on the effect of pressure on the mass transfer parameters in these reactors.

\subsubsection{Agitated reactors}

Four recent studies on mass transfer coefficients in stirred autoclaves for the gases $\mathrm{H}_{2}$ and $\mathrm{CO}$ and Fischer-Tropsch-type liquids exemplify the contradictory results concerning the effect of pressure. Albal et al. [10] determined volumetric liquid-phase mass transfer coefficients $k_{\mathrm{L}} a$ for $\mathrm{H}_{2}$ and $\mathrm{CO}$ in molten paraffin wax at pressures ranging from 1 to 3.5 MPa. They worked under conditions of surface aeration and observed that $k_{\mathrm{L}} a$ was independent of the operating pressure. Deimling et al. [21] used the same installation and determined $k_{\mathrm{L}} a$ for $\mathrm{H}_{2}$ and $\mathrm{CO}$ in three Fischer-Tropsch-type liquids at pressures 


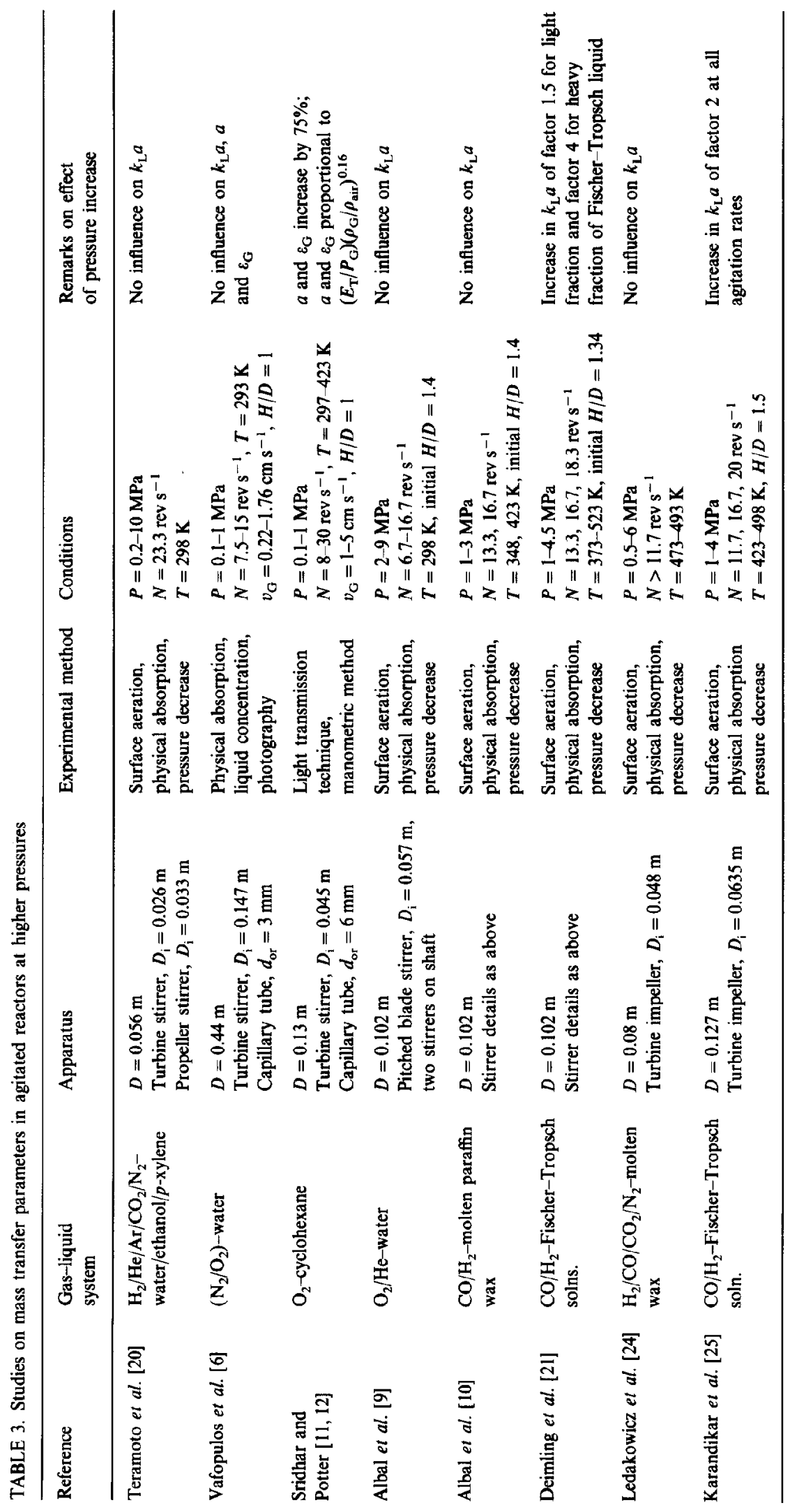




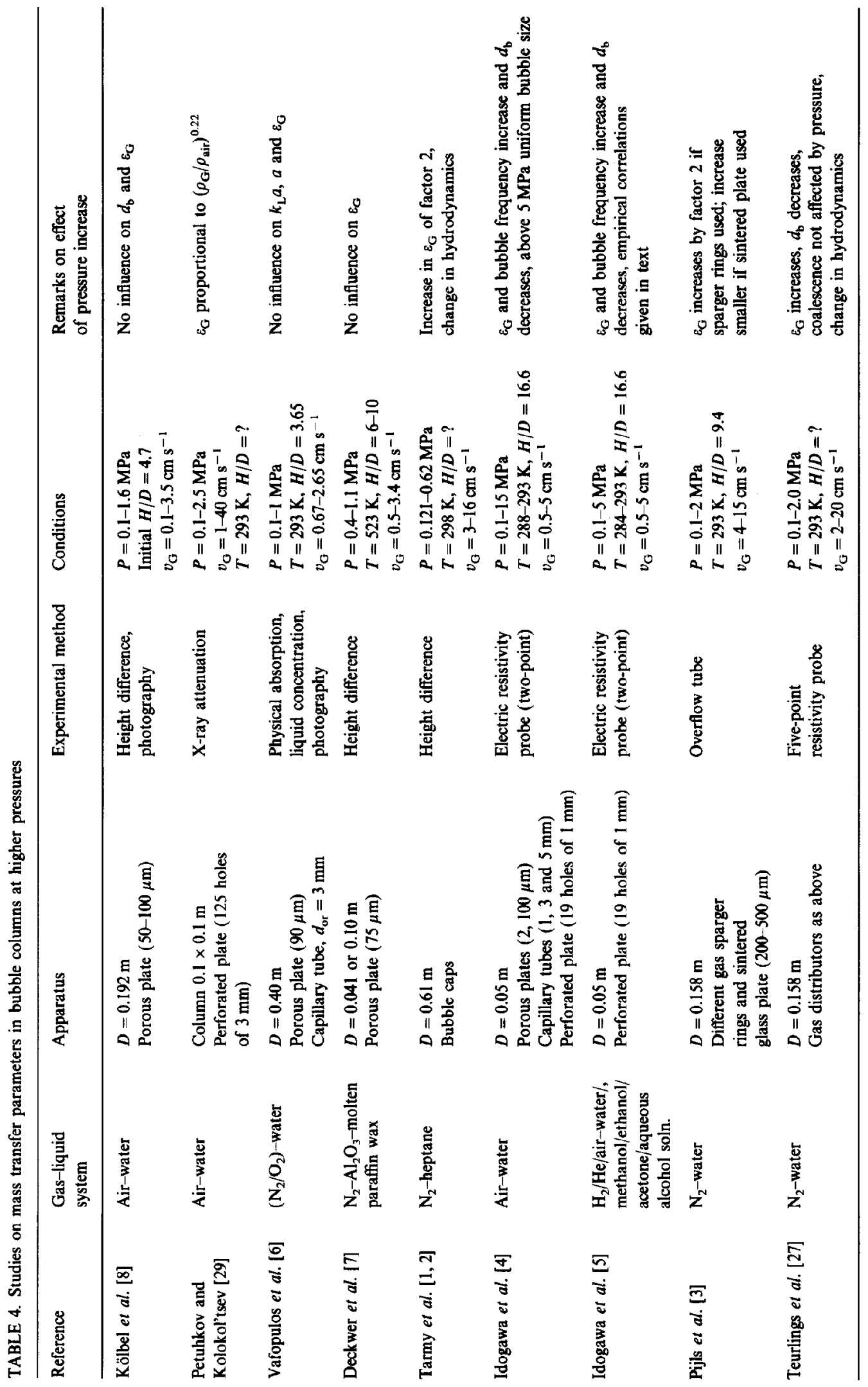


ranging from 1 to $4.5 \mathrm{MPa}$. For a pressure increase from 1 to $4 \mathrm{MPa}$ for both gases they observed a strong effect of pressure, resulting in $k_{\mathrm{L}} a$ being increased by a factor of about 1.5 for the light fraction and a maximum of $\mathbf{4}$ for the heavy fraction. According to these authors this is mainly due to the effect of pressure on the interfacial area $a$. They suggest that $a$ increases with pressure because of the change in surface tension, which is around $40 \%$ for the pressure range and liquids used. This results in the formation of smaller entrained bubbles. Addition of inert solids did not change this strong pressure effect. Ledakowicz et al. [24], using the same experimental technique as mentioned above, reported $k_{\mathrm{L}} a$ data for $\mathrm{H}_{2}, \mathrm{CO}, \mathrm{N}_{2}$ and $\mathrm{CO}_{2}$ in a molten wax under FischerTropsch conditions and pressures between 0.1$6 \mathrm{MPa}$. They did not observe any effect of pressure. In contrast, at pressures between 1 and $4 \mathrm{MPa}$, Karandikar et al. [25] again found a pronounced influence of pressure on $k_{\mathrm{L}} a$ for $\mathrm{H}_{2}$ and $\mathrm{CO}$ in a medium fraction of Fischer-Tropsch-type liquid. At all agitation rates their data show an increase in $k_{\mathrm{L}} a$ by a factor of 2 at a pressure increase from 1 to $4 \mathrm{MPa}$.

All the studies are summarized in Fig. 6 in which a normalized volumetric liquid-phase mass transfer coefficient is plotted against pressure. Karandikar et al. [25] gave no explanation for the pressure effect, but from these four studies, in which the same experimental method and gas-liquid systems were used, it is evident that, even if there is any effect of pressure on $k_{\mathrm{L}} a$, its magnitude is probably dependent on the specific surface properties of the liquid phase.

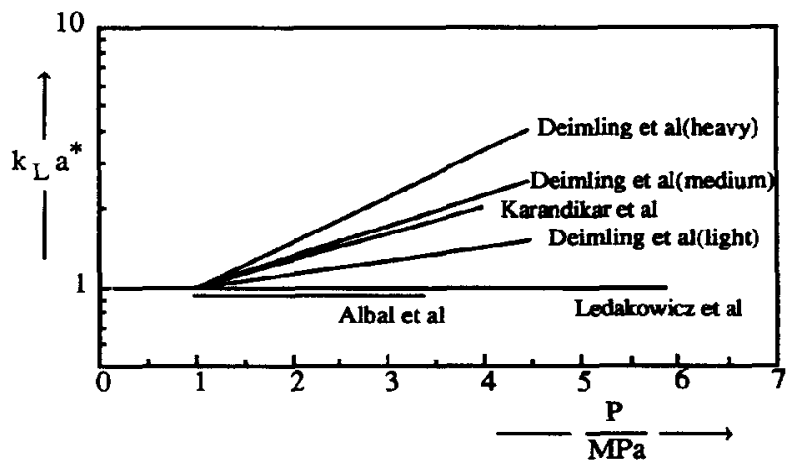

Fig. 6. Normalized volumetric liquid-phase mass transfer coefficient against the pressure in surface aerated agitated reactors.

\begin{tabular}{llc}
\hline Reference & Liquid & $N\left(\right.$ rev s $\left.^{-1}\right)$ \\
\hline $\begin{array}{l}\text { Albal } \text { et al. }[10] \\
\begin{array}{l}\text { Ledakowicz } \\
\text { et al. }[24]\end{array}\end{array}$ & $\begin{array}{l}\text { Paraffin wax } \\
\text { Deimling } \text { et al. }[21]\end{array}$ & $\begin{array}{c}\text { Fischer-Tropsch- } \\
\text { type liquids }\end{array}$ \\
$\begin{array}{l}\text { Karandikar } \\
\text { et al. }[25]\end{array}$ & $\begin{array}{c}\text { Fischer-Tropsch } \\
\text { soln. }\end{array}$ & 11.7 \\
\hline
\end{tabular}

The same experimental technique has also been used by Albal et al. [9] and by Teramoto et al. [20] to determine $k_{\mathrm{L}} a$ data for $\mathrm{H}_{2}, \mathrm{O}_{2}$ and $\mathrm{N}_{2}$ in water. They worked at pressures from 0.2 to $1.0 \mathrm{MPa}$ and neither group found any influence of pressure on $k_{\mathrm{L}} a$.

Contradictory results regarding the influence of pressure can also be found in sparged mechanically agitated reactors. Working with an air - water system at pressures between 0.1 and $1 \mathrm{MPa}$, Vafopulos et al. [16] found no influence of pressure on $k_{\mathrm{L}} a, a$ or $\varepsilon_{\mathrm{G}}$ in a mechanically agitated reactor. Within the same pressure range Sridhar and Potter [11,12] observed an increase of as much as $75 \%$ of the interfacial area in a mechanically agitated reactor with the system $\mathrm{O}_{2}$-cyclohexane. Sridhar and Potter $[11,12]$ attributed this increase of the mass transfer parameters to the increase with pressure of the kinetic energy content of the inlet gas flow. To correlate their results they modified the equations of Calderbank [26] by multiplying them by a factor $\left(E_{\mathrm{T}} / P_{\mathrm{G}}\right)\left(\rho_{\mathrm{G}} /\right.$ $\left.\rho_{\text {air }}\right)^{0.16}$, where the first factor represents the ratio of the total (kinetic and mechanical) energy supplied to the dispersion and the power input by agitation only. A second correction factor for the gas density had to be applied, so it was not possible to account for the influence of pressure solely by the increase in the kinetic energy content of the gas flow.

\subsubsection{Bubble columns}

That not only the increase in the kinetic energy content is responsible for the increase in gas hold-up with pressure has been confirmed for a bubble column by Pijls et al. [3]. They found a twofold increase in gas hold-up for a pressure increase from 0.1 to $2 \mathrm{MPa}$. They used an $\mathrm{N}_{2}$-water system and different sparger rings and concluded that neither an increase in the kinetic energy nor in the momentum of the gas flow can account for the increase in the gas hold-up. They also observed a smaller pressure effect with a sintered glass plate than with the sparger rings. Pijls et al. [3] explain their results qualitatively by a simultaneous decrease of the initial diameter and of the coalescence rate of the bubbles with an increase of pressure. Teurlings et al. [27] determined bubble diameters in the same experimental system with a multipoint resistivity probe. Again they found a pronounced effect of pressure on the gas hold-up. This influence was smaller for the sintered glass plate as gas distributor. They observed a decrease in the average bubble diameter in the column with increasing pressure. Bubble size distributions were measured at different heights in the bubble column and at different pressures: it could be concluded that the coalescence of bubbles was not influenced by pressure. Teurlings et al. [27] also observed that with increasing pressure the fraction of fast moving bubbles becomes smaller. According to them this indicates a change in the hydrodynamics: at higher pressures the transition from the bubbling regime towards the churn-turbulent regime [28] occurs at higher gas velocities. 
Tarmy et al. [1,2] reported on gas hold-up measurements in a bubble column with $\mathrm{N}_{2}$-heptane as the gas-liquid system and bubble caps as gas distributors. They varied the pressures between 0.12 and $0.62 \mathrm{MPa}$ and found a strong pressure influence. The gas hold-ups at $0.62 \mathrm{MPa}$ were about twice those at $0.12 \mathrm{MPa}$. Tarmy et al. $[1,2]$ also calculated that a change in flow regime occurs: at higher pressures the transition from the uniform bubbling regime to the churn-turbulent regime occurs at higher gas velocities and gas hold-ups [28]. According to them the fact that the bubbling regime persists at higher gas hold-ups indicates that at higher pressures very small, noncoalescing bubbles are present in the system.

With an electric resistivity probe, Idogawa $e t$ al. [4] studied the behaviour of bubbles in the system air-water in a bubble column. They used different gas distributors and worked at pressures ranging from 0.1 to $15 \mathrm{MPa}$. With an increase in pressure the gas hold-up and bubble frequency increased, while the bubble size decreased. Above 5 MPa the bubble size distributions became narrow and the size of the bubbles almost uniform. The effect of pressure was much smaller when porous plates were used as gas distributors instead of single orifices or a perforated plate. In a second study, Idogawa et al. [5] extended their research to other systems, consisting of $\mathrm{H}_{2}$, He or air as gases and of water, methanol, ethanol, acetone or aqueous solutions of alcohols as liquids. In these experiments the pressure ranged from 0.1 to $5 \mathrm{MPa}$, and a perforated plate with 19 holes of $1 \mathrm{~mm}$ diameter was used as the gas distributor. The following correlations were obtained for the gas hold-up and the average bubble diameter:

$\frac{\varepsilon_{\mathrm{G}}}{1-\varepsilon_{\mathrm{G}}}=1.44 v_{\mathrm{G}}{ }^{0.58} \rho_{\mathrm{G}}{ }^{0.12} \sigma_{\mathrm{L}}{ }^{-0.16 \exp (-P)}$

$d_{\mathrm{b}}=3.10 \times 10^{-3} \rho_{\mathrm{G}}^{-0.028} \sigma_{\mathrm{L}}^{0.088 \exp (-P)}$

In these expressions SI units have to be used, except for the pressure $P$ and the surface tension $\sigma_{\mathrm{L}}$, which have to be expressed in $\mathrm{MPa}$ and $\mathrm{mN} \mathrm{m} \mathrm{m}^{-1}$ respectively. Their experimental range was $v_{\mathrm{G}}=0.5 \times$ $10^{-2}$ to $5 \times 10^{-2} \mathrm{~m} \mathrm{~s}^{-1}, \rho_{\mathrm{G}}=0.084$ to $120.8 \mathrm{~kg} \mathrm{~m}^{-3}$, $\sigma_{\mathrm{L}}=22.6$ to $72.1 \mathrm{mN} \mathrm{m}^{-1}$ and $P=0.1$ to $5 \mathrm{MPa}$. For air-water at a constant superficial gas velocity of $1 \mathrm{~cm} \mathrm{~s}^{-1}$ these correlations predict an increase in the gas hold-up by a factor of 2.7 and a decrease in the average bubble diameter by a factor of 0.6 , when the pressure is increased from 0.1 to $5 \mathrm{MPa}$; this results in an increase in the interfacial area by a factor of 4.5 .

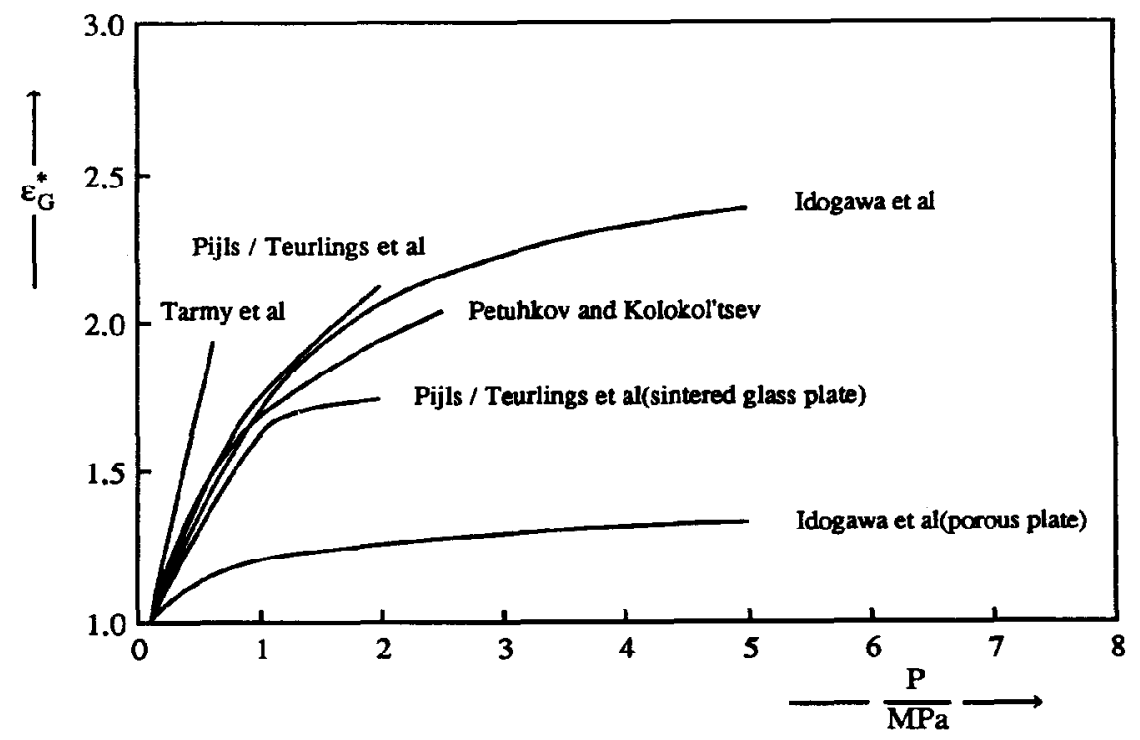

Fig. 7. Normalized hold-up against the pressure in bubble columns.

\begin{tabular}{|c|c|c|c|}
\hline Reference & Gas-liquid system & Gas distributor & $v_{G}\left(\mathrm{~cm} \mathrm{~s}^{-1}\right)$ \\
\hline $\begin{array}{l}\text { Pijls et al. [3] } \\
\text { Teurlings et al. [27] }\end{array}$ & $\mathbf{N}_{2}$-water & Sparger ring $(46 \times 2.75 \mathrm{~mm})$ & 10 \\
\hline $\begin{array}{l}\text { Pijls et al. [3] } \\
\text { Teurlings et al. [27] }\end{array}$ & $\mathbf{N}_{2}$-water & Sintered glass plate $(200-500 \mu \mathrm{m})$ & 10 \\
\hline Tarmy et al. $[1,2]$ & $\mathbf{N}_{2}$-heptane & Bubble caps & 10 \\
\hline Idogawa et al. [4] & Air-water & Perforated plate $(19 \times 1 \mathrm{~mm})$ & 5 \\
\hline Idogawa et al. [4] & Air-water & Porous plate $(100 \mu \mathrm{m})$ & 3 \\
\hline Petuhkov and Kolokol'tsev [29] & Air-water & Perforated plate $(125 \times 3 \mathrm{~mm})$ & $1-40$ \\
\hline
\end{tabular}


Petuhkov and Kolokol'tsev [29] studied liquid entrainment in a bubble column with air-water as the gas-liquid system at pressures from 0.1 to $2.5 \mathrm{MPa}$. At pressures of $0.1,0.3$ and $2.5 \mathrm{MPa}$ they also determined the gas hold-up and found that it was proportional to $\left(\rho_{\mathrm{G}} / \rho_{\mathrm{L}}\right)^{0.22}$.

All these six studies indicate that pressure has an effect on the gas hold-up and bubble diameters in a bubble column (see Fig. 7). In contradiction to these studies Vafopulos et al. [6], Deckwer et al. [7] and Kölbel et al. [8] found no influence of pressure on the gas hold-up and bubble diameters in two- and three-phase bubble columns.

Kölbel et al. [8] worked at pressures between 0.1 and $1.6 \mathrm{MPa}$ in a bubble column with air-water as the gas-liquid system and a porous plate as gas distributor. They determined bubble diameters by photography and could find no influence of pressure. They also measured gas hold-ups by the height difference method and found them to be independent of the operating pressure. Vafopulos et al. [6], who used the same experimental technique, also reported bubble diameters and gas hold-ups to be independent of pressure in a bubble column. They also worked with air-water as the gas-liquid system and a porous plate or a capillary tube as gas distributor at pressures from 0.1 to $1 \mathrm{MPa}$. Besides bubble diameters and gas hold-ups Vafopulos et al. [6] determined the volumetric liquid-phase mass transfer coefficients $k_{\mathrm{L}} a$ by physical absorption and found them to be independent of pressure.

Deckwer et al. [7] studied the influence of pressure on the gas hold-up at pressures from 0.4 to $1.1 \mathrm{MPa}$ in two bubble columns with a porous plate as gas distributor and the three-phase system $\mathrm{N}_{2}-\mathrm{Al}_{2} \mathrm{O}_{3}-$ molten paraffin wax. In agreement with Kölbel et al. [8] and Vafopulos et al. [6] they found no influence of the operating pressure on the gas hold-up.

Altogether, there seems to be a lot of disagreement between the various authors on the influence of pressure on the overall mass transfer parameters $k_{\mathrm{L}} a$, $a$ and the gas hold-up $\varepsilon_{\mathrm{G}}$ in agitated reactors and bubble columns. However, when the operating conditions and experimental systems are considered more closely, some specific remarks can be made, as will be done in the next section.

\section{Discussion}

All studies on the bubble formation at a single orifice in a pressurized gas-liquid system indicate a decrease in the initial bubble size when the pressure increases. This decrease is larger when the orifice is connected to a gas chamber instead of using only a capillary tube. Modelling of the experimental results was only partly successful. LaNauze and Harris [14] modelled their experiments at higher pressures with a modified version of the bubble growth model of Davidson and Schüler [30]. They extended this model to allow for the rate of change of gas momentum and for varying gas chamber pressures. Their model showed good agreement with their experimental results at lower flow rates, but discrepancies occur at higher flow rates, because the theory deals with single bubbles only and assumes no interaction of bubbles. For an orifice connected to a gas chamber, as well as their results for a capillary tube, Bier $e t$ al. [15] compared their results with the semi-empirical diagrams for bubble formation at a single orifice given by Mersmann [31]. These diagrams are based on the two-step bubble formation model of Kumar and Kuloor [32], which assumes a constant gas flow rate during the bubble formation process. Excellent agreement was found between the experimental results with a capillary tube and the prediction by the diagrams, but for an orifice connected to a gas chamber the results showed considerable deviations. Bier et al. [15] argued that this probably is caused by the fact that the gas flow rate is irregular during the bubble formation at an orifice connected to a gas chamber, while it is approximately constant for the capillary tube. Finally, they correlated their results successfully with an empirical correlation, but unfortunately this correlation is specific to their experimental configuration and conditions.

Therefore at this moment it does not seem possible to predict the initial bubble volume at a single orifice in pressurized gas-liquid systems. However, the qualitative results can be used for a better understanding of the influence of pressure in gas-liquid reactors on the overall mass transfer parameters $k_{\mathrm{L}} a$, $a$ and the gas hold-up $\varepsilon_{\mathrm{G}}$. Besides this, one may wonder whether correlations for the initial bubble diameter are useful to the designer of pressurized gas-liquid reactors, because considerable coalescence is known to take place in the vicinity of the gas sparger.

The influence of pressure on the gas-and liquidphase mass transfer coefficients $k_{\mathrm{G}}$ and $k_{\mathrm{L}}$ can be divided into the effect of pressure on the hydrodynamics of the phase and its effect on the physical properties of the phase under consideration. Important liquid-phase properties like the viscosity, the specific gravity and the diffusivity of the transferred component in the liquid phase are only affected to any considerable extent at extremely high pressures. In contrast, the gas-phase density and the diffusivity in the gas phase are indeed affected by pressure in a manner that is approximately proportional to the pressure. As shown by Versteeg et al. [23] (see Fig. 5) this results in considerable influence of pressure on the gas-phase mass transfer coefficient $k_{\mathrm{G}}$.

The changes with pressure in the bubbling regimes at a single orifice and in the flow regimes in a bubble column, as reported respectively by Idogawa et al. [17] and Tarmy et al. [1, 2], indicate the possibility of a pressure effect on the hydrodynamics in gas-liquid reactors. This most certainly will affect the characteristic mass transfer parameter (film thickness or surface renewal time) of the prevailing mass transfer model or even the applicability of the mass transfer model itself. Changes with pressure in the gas holdup and bubble diameters may also influence the mass 
transfer coefficients. Furthermore, Massoudi and King [33] and Sagert and Quinn [34] reported a pressure influence on the surface tension and also on the apparent viscosity of the surface of different gas-liquid systems, which may affect the hydrodynamics of the phases. With this in mind, we should be very careful in stating that the liquid-phase mass transfer coefficient $k_{\mathrm{L}}$ is independent of pressure if we are not absolutely sure that the hydrodynamics of the gas-liquid system are not affected by the pressure.

The results in surface aerated agitated reactors of the four studies under Fischer-Tropsch conditions and the two with water show no similar pressure effect on the volumetric liquid-phase mass transfer coefficient $k_{\mathrm{L}} a$. However, there seems to be a specific relation between the pressure and the liquid phase used. It is possible to distinguish between the studies with Fischer Tropsch-type liquids $[21,25]$ and those with water $[9,20]$ and molten waxes $[10,24]$. The studies with the Fischer-Tropsch-type liquids show a pronounced effect of pressure, which is even dependent on the composition of the liquid (see Fig. 6 and ref. 21). Both the studies in water and with molten waxes show no influence of pressure at all. In our view this indicates that specific gas-liquid interaction parameters such as the surface tension and the foaming characteristics of the liquid could have a strong influence on the observed pressure effect. Whether these specific gas-liquid interactions are also responsible for the contradictory results found in sparged agitated reactors by Vafopulos et al. [6] and Sridhar and Potter [11, 12], who used water and cyclohexane respectively, cannot be concluded.

A critical review of all studies on the influence of the operating pressure on the overall mass transfer parameters $k_{\mathrm{L}} a$, a and the gas hold-up $\varepsilon_{\mathrm{G}}$ in bubble columns leads to the following three remarks.

(1) All three studies which claimed that no pressure influence exists used a porous plate $(<100 \mu \mathrm{m})$ as gas distributor. The other studies used different gas distributors and, when they too used porous plates, they observed a much smaller pressure effect (see Fig. 7: sintered glass plate $(200-500 \mu \mathrm{m})[3,27]$; porous plates $(2,100 \mu \mathrm{m})[4])$.

(2) It is not possible to make a distinction between the studies in bubble columns on the basis of the liquids used, as was the case with the surface aerated agitated reactors. Vafopulos et al. [6] and Kölbel et al. [8] used water as the liquid and did not find a pressure effect. On the contrary, Pijls et al. [3], Idogawa et al. [4,5], Teurlings et al. [27] and Petuhkov and Kolokol'tsev [29] all found a pronounced pressure effect in their water-containing systems. The same findings hold for organic liquids, where Tarmy et al. [1,2] and Idogawa et al. [5] found a pronounced pressure influence, while Deckwer et al. [7] observed no effect at all.

(3) In all three studies which claimed that no influence of pressure exists, low superficial gas velocities between 0.1 and $3.5 \mathrm{~cm} \mathrm{~s}^{-1}$ were applied. In most studies in which an influence of pressure was found, higher gas velocities between 2 and $20 \mathrm{~cm} \mathrm{~s}^{-1}$ were used. The studies of Idogawa et al. $[4,5]$, who found a pressure effect when working with rather low superficial gas velocities between 0.5 and $5 \mathrm{~cm} \mathrm{~s}^{-1}$, are an exception.

Bubbles formed at a porous plate have a rather broad size distribution and interact vigorously with each other on the surface of the porous plate. This could easily lead to coalescence of the bubbles and so disguise a pressure effect on the bubble formation process at a porous plate. This could be the reason why most studies with porous plates show no effect of pressure on $k_{\mathrm{L}} a, a$ and $\varepsilon_{\mathrm{G}}$. Another possibility is that a pressure effect may occur only at higher superficial gas velocities.

The change in flow regimes with an increase in pressure, as reported by Tarmy et al. [1,2] and Teurlings et al. [27], can be explained by the formation of smaller bubbles at higher pressures. These bubbles have lower rising velocities leading to an increase in the gas hold-up. It is interesting to note that this may result in the operation of a bubble column still in the bubbling regime at high gas hold-ups and at higher pressures. In the work of Tarmy et al. [1,2] it can be seen that at a gas hold-up of $\varepsilon_{\mathrm{G}}=0.3$ and at $P=0.62 \mathrm{MPa}$ the bubble column still operates in the bubbling regime, while at atmospheric pressure the change from the bubbling regime towards the churn-turbulent regime normally occurs at gas hold-ups between 0.10 and 0.15 [28]. The combination of decreasing bubble diameters and increasing gas hold-ups can result in a spectacular increase in the interfacial areas. This was already shown with the correlations of Idogawa et al. [5] in eqns. (3) and (4), which give an increase of a factor of 4.5 in the interfacial area for an increase in pressure from 0.1 to $5 \mathrm{MPa}$ for water at $v_{\mathrm{G}}=1 \mathrm{~cm} \mathrm{~s}^{-1}$.

\section{Conclusions}

We may draw the following conclusions after reviewing the papers mentioned.

(1) The initial bubble size at a single orifice decreases with increasing pressure. The effect is larger if an orifice connected to a gas chamber is used instead of a capillary tube.

(2) The critical gas velocity separating the multiple bubbling and jetting regimes at a single orifice decreases with increasing pressure.

(3) The gas-phase mass transfer coefficient $k_{\mathrm{G}}$ is inversely proportional to pressure to the power 0.5 . This exponent is in accordance with the penetration theory.

(4) The liquid-phase mass transfer coefficient $k_{\mathrm{L}}$ is not influenced by pressure, provided the liquidphase hydrodynamics are unaffected by pressure.

(5) The influence of pressure on the volumetric liquid-phase mass transfer coefficient $k_{\mathrm{L}} a$ in surface aerated agitated reactors seems to depend on specific 
gas-liquid interaction parameters like the surface tension and the foaming characteristics.

(6) The gas hold-up $\varepsilon_{G}$ in bubble columns increases with increasing pressure. The influence of pressure is much smaller or even absent if a porous plate is used as the gas distributor.

(7) In bubble columns at higher pressures the transition from the uniform bubbling regime towards the churn-turbulent regime occurs at higher superficial gas velocities and at higher gas hold-ups than at atmospheric pressure.

\section{Acknowledgements}

The investigations were supported by the Netherlands Foundation for Chemical Research (SON) with financial aid from the Netherlands Organization for the Advancement of Scientific Research (NWO).

\section{Nomenclature}

a specific interfacial area, $\mathrm{m}^{2} / \mathrm{m}^{3}$ dispersion

$D$ reactor diameter, $\mathrm{m}$

$D_{\mathrm{i}} \quad$ impeller diameter, $\mathrm{m}$

d diameter, $\mathrm{m}$

$E_{\mathrm{T}}$ total energy input into dispersion, W

$H$ dispersion height, $\mathrm{m}$

$k$ mass transfer coefficient, $\mathrm{m} \mathrm{s}^{-1}$

$N \quad$ agitation rate, $\mathrm{s}^{-1}$

$n \quad$ exponent

$P \quad$ pressure, $\mathrm{Pa}$

$P_{\mathrm{G}} \quad$ gassed power input, $\mathrm{W}$

$\operatorname{Re}_{\mathrm{G}, \text { or }}=v_{\mathrm{G} \text {, or }} d_{\mathrm{or}} / v_{\mathrm{G}}$, orifice Reynolds number

$T$ temperature, $\mathrm{K}$

$V$ volume, $\mathrm{m}^{3}$

$v$ superficial velocity based on empty cross-

sectional area of vessel, $\mathrm{m} \mathrm{s}^{-1}$

$\mathrm{We}_{\mathrm{or}} \quad=\rho_{\mathrm{L}} v_{\mathrm{G}, \text { or }} d_{\mathrm{or}} / \sigma$, orifice Weber number

$\varepsilon \quad$ hold-up

$v \quad$ kinematic viscosity, $\mathrm{m}^{2} \mathrm{~s}^{-1}$

$\rho$ density, $\mathrm{kg} \mathrm{m}^{-3}$

$\sigma$ surface tension, $\mathrm{N} \mathrm{m}^{-1}$

$\phi \quad$ flow rate, $\mathrm{m}^{3} \mathrm{~s}^{-1}$

\section{Subscripts}

$\begin{array}{ll}\text { air } & \text { air } \\ \text { AR } & \text { agitated reactor } \\ \text { b } & \text { bubble } \\ \text { BC } & \text { bubble column } \\ \text { cr } & \text { critical } \\ \text { G } & \text { gas } \\ \text { L } & \text { liquid } \\ \text { or } & \text { orifice }\end{array}$

\section{Superscripts}

* normalized to atmospheric conditions

\section{References}

I B. L. Tarmy, M. Chan, C. A. Coulaloglou and P. R. Ponzi, Hydrodynamic characteristics of three phase reactors, Chem. Eng., (Oct.) (1984) 18-23.

2 B. L. Tarmy, M. Chan, C. A. Coulaloglou and P. R. Ponzi, The three phase hydrodynamic characteristics of the EDS coal liquefaction reactors; their development and scaleup, Inst. Chem. Eng. Symp. Ser. No. 87, (1984) 303-317.

3 N. J. M. Pijls, D. Thoenes and L. L. van Dierendonck, Personal communication, Eindhoven Univ., 1985.

4 K. Idogawa, K. Ikeda, T. Fukuda and S. Morooka, Behavior of bubbles of the air-water system in a column under high pressure, Int. Chem. Eng., 26 (1986) 468-474.

$5 \mathrm{~K}$. Idogawa, K. Ikeda, T. Fukuda and S. Morouka, Efrect of gas and liquid properties on the behavior of bubbles in a column under high pressure, Int. Chem. Eng., 27 (1987) 93-99.

6 I. Vafopulos, K. Sztatecsny and F. Moser, Der EinfluB des Partial- und Gesamtdruckes auf den Stoffaustausch, Chem.Ing.-Tech., 47 (1975) 681.

7 W.-D. Deckwer, Y. Louisi, A. Zaidi and M. Ralek, Hydrodynamic properties of the Fischer-Tropsch slurry process, Ind. Eng. Chem., Process Des. Dev., 19 (1980) 699-708.

8 H. Kölbel, E. Borchers and H. Langemann, Größenverteilung der Gasblasen in Blasensäulen. Teil 1: Einflüße von Flüssigkeitsviskosität und Säuleninnendruck, Chem.-Ing.-Tech., 33 (1961) 668-675.

9 R. S. Albal, Y. T. Shah, A. Schumpe and N. L. Carr, Mass transfer in multiphase agitated contactors, Chem. Eng. J., 27 (1983) 61-80.

10 R. S. Albal, Y. T. Shah, N. L. Carr and A. T. Bell, Mass transfer coefficients and solubilities for hydrogen and carbon monoxide under Fischer-Tropsch conditions, Chem. Eng. Sci., 39 (1984) 905-907.

11 T. Sridhar and $O$. E. Potter, Interfacial areas in gas-liquid stirred vessels, Chem. Eng. Sci., 35 (1980) 683-695.

12 T. Sridhar and O. E. Potter, Gas hold-up and bubble diameters in pressurized gas-liquid stirred vessels, Ind. Eng. Chem., Fundam., 19 (1980) 21-26.

13 G. Kling, Uber die Dynamik der Blasenbildung beim Begasen von Flüssigkeiten unter Druck, Int. J. Heat Mass Transfer, 5 (1962) 211-223.

14 R. D. LaNauze and I. J. Harris, Gas bubble formation at elevated pressures, Trans. Inst. Chem. Eng., 52 (1974) 337-348.

$15 \mathrm{~K}$. Bier, D. Gorenflo and J. Kemnade, Bubble formation and interfacial area during injection of gases into liquids through single orifices. Part 2: Effect of the system pressure and of thermophysical properties on bubble volume and specific interfacial area, Wärme-Stoffübertrag., 11 (1978) 217-228.

$16 \mathrm{~K}$.-D. Kaufmann, Vergleich verschiedener Methoden der Phasengrenzflächenmessung in Blasensäulen unter Einbeziehung höherer Drücke, Ph.D. Thesis, Munich Univ., 1981.

17 K. Idogawa, K. Ikeda, T. Fukuda and S. Morooka, Formation and flow of gas bubbles in a pressurized bubble column with a single orifice or nozzle gas distributor, Chem. Eng. Commun., 59 (1987) 201-212.

$18 \mathrm{~N}$. H. Sagert and M. J. Quinn, The coalescence of $\mathrm{H}_{2} \mathrm{~S}$ and $\mathrm{CO}_{2}$ bubbles in water, Can. J. Chem. Eng., 54 (1976) 392-398.

19 F. Yoshida and S. Arakawa, Pressure dependence of liquid phase mass transfer coefficients, AIChE J., 14 (1968) 962-963.

$20 \mathrm{M}$. Teramoto, S. Tai, K. Nishii and H. Teranishi, Effects of pressure on liquid phase mass transfer coefficients, Chem. Eng. $J ., 8$ (1974) 223-226.

21 A. Deimling, B. M. Karandikar, Y. T. Shah and N. L. Carr, Solubility and mass transfer of $\mathrm{CO}$ and $\mathrm{H}_{2}$ in Fischer-Tropsch liquids and slurries, Chem. Eng. J., 29 (1984) 127-140.

22 J. M. Prausnitz, R. C. Reid and T. K. Sherwood, The Properties of Gases and Liquids, McGraw-Hill, New York, 3rd edn., 1977. 
23 G. F. Versteeg, P. M. M. Blauwhoff and W. P. M. van Swaaij, The effect of diffusivity on gas-liquid mass transfer in stirred vessels. Experiments at atmospheric and elevated pressures, Chem. Eng. Sci., 42 (1987) 1103-1119.

24 S. Ledakowicz, H. Nettelhof and W.-D. Deckwer, Gas-liquid mass transfer data in a stirred autoclave reactor, Ind. Eng. Chem., Fundam., 23 (1984) 510-512.

25 B. S. Karandikar, B. I. Morsi, Y. T. Shah and N. L. Carr, Effect of water on the solubility and mass transfer coefficients of $\mathrm{CO}$ and $\mathrm{H}_{2}$ in a Fischer-Tropsch liquid, Chem. Eng. J., 33 (1986) $157-168$.

26 P. H. Calderbank, Physical rate processes in industrial fermentation. Part 1: The interfacial area in gas-liquid contacting with mechanical agitation, Trans. Inst. Chem. Eng., 36 (1958) 443463.

27 A. Teurlings, D. Thoenes and L. L. van Dierendonck, Personal communication, Eindhoven Univ., 1986.

28 Y. T. Shah, B. G. Kelkar, S. R. Godbole and W.-D. Deckwer,
Design parameters estimations for bubble column reactors, AIChE J., 28 (1982) 353-379.

29 V. I. Petuhkov and V. A. Kolokol'tsev, Effect of liquid viscosity on droplet entrainment and volumetric air content, Therm. Eng. (USSR), 12 (1965) 41-44.

30 J. F. Davidson and B. O. G. Schüler, Bubble formation at an orifice in a viscous liquid, Trans. Inst. Chem. Eng., 38 (1960) 144-154.

31 A. Mersmann, Auslegung and Maßstabsvergrößerung von Blasen- und Tropfensäulen, Chem.-Ing.-Tech., 49 (1977) 679 691.

32 R. Kumar and N. R. Kuloor, The formation of bubbles and drops, Adb. Chem. Eng., 8 (1970) 255-368.

33 R. Massoudi and A. D. King, Effect of pressure on the surface tension of water. Adsorption of low molecular weight gases on water at $25^{\circ} \mathrm{C}$, J. Phys. Chem., 78 (1974) 2262-2266.

34 N. H. Sagert and M. J. Quinn, Surface viscosities at high pressure gas liquid interfaces, J. Colloid Interface Sci., 65(1978) 415-422. 